\title{
Risk assessment of leukaemia and occupational exposure to benzene
}

\author{
G M H SWAEN, J M M MEIJERS \\ From the Department of Occupational Health and Toxicology, University of Limburg, 6200 MD Maastricht, \\ The Netherlands
}

ABSTRACT Experimental toxicological studies have offered clear evidence that benzene induces haematopoietic neoplasms, and it is generally accepted that exposure to benzene is a risk factor foo leukaemia, in particular for acute non-lymphatic leukaemia. Quantitative aspects of benzene ris assessment are still a matter of controversy, however. In several risk assessments an estimated $5 \overrightarrow{\hat{\theta}^{\circ}}$ deaths from leukaemia per 1000 deaths would arise from exposures to benzene of $10 \mathrm{ppm}$ during $\overrightarrow{\mathrm{A}}$ working life of 30 years. The assessment presented in this paper leads to lower estimates, which aris more in agreement with the weak toxicological data. Furthermore, an approach is presented to incorporate the results of low exposure epidemiological studies into the process of quantitative ris $\mathrm{K}$ assessment.

In the past decades a substantial body of knowledge has accumulated regarding the long term health effects of occupational exposure to benzene. In addition to experimental data, this consists of epidemiological data mainly from retrospective cohort studies of workers occupationally exposed to benzene. Except for the ability of benzene to cause non-malignant blood anomalies, the main chronic health effect of concern is the increased mortality due to leukaemia and, in particular, acute non-lymphatic leukaemia: several investigators have stated that this is the only increased risk after exposure to benzene. Nevertheless, other investigators have pointed out that benzene induces a variety of malignant neoplasms, including lymphatic leukaemia and lymphomas. ${ }^{1-3}$ The relation between exposure to high concentrations of benzene and the risk of leukaemia is well documented and generally accepted. Case reports and epidemiological confirmations have led to regulatory legislation throughout the world in the field of occupational exposure, and exposures experienced by the general population..$^{4-10}$ Several risk assessments have been conducted for occupational exposures. ${ }^{11-15}$ In a recent review the authors presented a risk assessment based on the results of a retrospective cohort study of 1006 exposed workers, applying a linear dose-response relation. ${ }^{15}$

Accepted 13 February 1989
Following a request from the Minister of Welfare? Public Health and Culture, a committee of the Heditto Council of The Netherlands has drawn up a somew different risk assessment for the risk of leukaemia a a exposure to benzene in ambient air. It is the purpese of this article to apply this risk assessment to occupational exposures to benzene.

Several weaknesses of epidemiological data can bo identified that may form a source of controversy. The first weakness is the lack of accurate and reliable dat regarding the exposure levels that existed in the past and have been experienced by the studied cohort This is not a particular problem in the course of a qualitative risk assessment: in other words to assess $\$$ exposure to high concentrations of a certain chemica is a risk factor for a particular neoplasm. In the course of a quantitative risk assessment, however, the estimation of past exposure will have substantial impact oQ the outcome of the assessment. A second weakness ox epidemiological data is the lack of information regard? ing the mechanisms, leading to the increased risks observed. Insight into the mechanism that is at work of great importance in the determination of the extrapolation model to be applied to assess the risks related to low exposure levels. The choice of the extrapolation model may also have a great impact of the outcome of the risk assessment. A major issue is whether or not the chemical should be considered genotoxic or not. In the case of a non-genotoxic agerf it is customary to take a no-effect level approach ane 
apply a safety factor to be on the safe side. In the case of a genotoxic agent a non-threshold approach is generally applied because it may be argued that even a small dose may provide a carcinogenic effect. The nonthreshold approach does not imply that the extrapolation model is linear or logistic. After a brief review of experimental toxicologic data of the carcinogenic potency of benzene, several remarks will be made regarding the available epidemiological data. Then the risk assessment proposed by the Health Council of The Netherlands will be described.

\section{Experimental toxicological data}

Radioactive labelled benzene has been reported to be incorporated into nucleic acids in the liver, spleen, bone marrow, and kidney cell of mice and rats. ${ }^{16-18}$ Several recent publications have made covalent binding of benzene metabolites to DNA even more plausible. ${ }^{1920}$ These investigations were conducted by means of isolated bone marrow mitochondria and their relevance for in vivo genotoxicity is at least questionable. Investigations of the effects of benzene on DNA repair and the occurrence of unscheduled DNA-synthesis in mammalian cell culture ${ }^{2122}$ and in bacteria ${ }^{23}$ have so far not yielded any evidence of DNA interaction. Despite extensive efforts there are no indications that benzene is capable of inducing gene mutations in bacteria, yeasts, drosphila, or mammalian cells if tests not capable of discriminating between gene mutations and recombinations are excluded. ${ }^{24}$ Benzene has been shown to be capable of inducing chromosome aberrations in yeast, fungi, insects, and somatic mammalian cells, including human lymphocytes. Chromosome breakage phenomena such as translocations have been found in vitro and in vivo in mammalian cells. These chromosome aberrations were observed with benzene concentrations lower than $10 \mathrm{ppm}$. Several in vivo experiments indicate that the sensitivity of laboratory animals to clastogenic effects indicate that the sensitivity of laboratory animals to clastogenic effects decreases with containing exposure. ${ }^{2526}$ Benzene has been tested for neoplastic transformation in a variety of test systems. Only in Syrian hamster cells was an increase in the incidence of transformed cell clones observed. ${ }^{27} 28$ Benzene is also capable of increasing the occurrence of tumours in Zymbal's gland, a comparatively rare organ for tumour formation in laboratory animals. ${ }^{29}$ On the basis of the multiple site carcinogenicity in animals, benzene may be considered as a potent carcinogen in animals and the carcinogenic process should in principle be viewed as a stochastic process.

\section{Epidemiological data}

After case reports were published indicating a possible relation between exposure to benzene and the occurrence of leukaemia, many epidemiological studies in this field were started and an extensive review has recently been published. ${ }^{\text {is }}$ The findings of these studies leave no doubt that workers exposed in the past to high concentrations of benzene have experienced an increased mortality from leukaemia. Both case-control studies and retrospective cohort studies have confirmed this relation. Several studies, however, in low exposure groups have reported contradictory results. For instance, in a retrospective cohort study of about 13500 workers in the rubber industry an excess mortality risk for lymphatic leukaemia was observed ${ }^{9}$ and not for non-lymphatic leukaemia as has been reported by other epidemiologists. In several other large studies of workers exposed to low concentrations of benzene no indications were found that these cohorts had experienced increased mortality for leukaemia. In a study of $38 \mathbf{8 0 0}$ workers employed in the petrochemical industry 18 cases of leukaemia were observed compared with an expected number of $23 .^{30}$ In a study of similar size (34 781 workers) in the oil industry 30 deaths from leukaemia were observed, compared with an expected number of $32 .^{31}$ In this study, however, a dose response relation appeared to exist, which was shown by means of a nested case-control study design. ${ }^{32}$ Again this casecontrol study confirmed the existence of a risk of leukaemia after exposure to high concentrations of benzene. A third study of workers exposed to benzene that should also be regarded as negative is the study conducted by Parkes et al in the British rubber industry.$^{33}$ In this study of 33815 workers, 31 cases of leukaemia were observed compared with an expected number of 28.

As has been pointed out by Hernberg, the interpretation of negative results of epidemiological studies is complicated. ${ }^{34}$ With a negative outcome, it is not always clear whether the finding is an effect of methodological deficiencies or if there actually is no increased risk present in the cohort and exposure level under investigation.

The greatest weaknesses of the three large studies of low exposures are the lack of quantitative exposure data and the possibility that a proportion of the "exposed cohort" had not been exposed to benzene at all. Despite these weaknesses, the committee of the Health Council of The Netherlands decided not to disregard these findings in establishing a risk assessment. Thus the committee was left with the task of incorporating positive results of high exposure studies and negative results of low exposure studies in a risk assessment, low exposures being defined as lower than 
a time weighted average exposure of $10 \mathrm{ppm}$ which is the current threshold unit value in many countries. This contradictory conception has also been supported by the European Chemical Industry Ecology and Toxicology Centre. ${ }^{35}$ As a consequence it was decided not to estimate an overall relative risk for leukaemia after exposure to benzene, as has been done in the evaluation of vinyl chloride. ${ }^{36}$ Two separate risk assessments were made, both based on the findings of epidemiological studies. The first departed from the findings in high exposure studies, the second from the findings in low exposure studies. Although the risk assessment conducted by the committee was intended for risks experienced by the general population, it may also be applied to the occupational environment.

\section{RISK ASSESSMENT BASED ON STUDIES OF HIGHLY EXPOSED WORKERS}

Before embarking on a risk assessment several assumptions must be made. The first deals with the magnitude of risk after a particular exposure dose. The second is concerned with the extrapolation model. The first assumption may be derived from several cohort studies. A reasonable estimate of this risk, based on Rinsky's risk assessment, is that workers exposed on average to $40 \mathrm{ppm}$ over a period of 10 years have experienced a fivefold increase in the risk of dying from acute non-lymphatic leukaemia $(S M R=500) .{ }^{13}$ Assuming a stochastic working mechanism, if a doubling of the dose also implies a doubling of the risk, a linear extrapolation model is suitable. Such a model may be formulated as:

$$
\text { SMR }=100+b \times d
$$

where SMR is the standardised mortality ratio (observed/expected $\times 100$ ), $b$ is the tangent of the angle between the straight line and the horizontal axis (dose), and $\mathrm{d}$ is the benzene dose in ppm-years. By means of this model the number of additional deaths from leukaemia per 1000 deaths which may arise from a benzene dose of $300 \mathrm{ppm}$-years may be calculated, as done by Austin et al ${ }^{15}$ :

$$
\begin{gathered}
500=100+b \times 400 \rightarrow b=1 \\
\text { if } d=300 \text { ppm-years then SMR }= \\
100+1 \times 300=400
\end{gathered}
$$

Thus workers having received a total benzene dose of $300 \mathrm{ppm}$-years may experience a SMR of 400 .

In a western country such as The Netherlands the age adjusted death rate for acute non-lymphatic leukaemia in men is 1.6 per $100000^{37}$ and the total mortality is 923.2 per 100000 . This implies that about 1.7 deaths per 1000 deaths are due to acute nonlymphatic leukaemia. In a population in which an SMR of 400 exists $4 \times 1.7=6.8$ deaths due to acute non-lymphatic leukaemia may occur per 1000 deaths, which is an excess of about five deaths. This estimate differs from that proposed by Austin ${ }^{15}$ which is in $\overline{\text { 夏 }} \epsilon$ range of about 50 excess deaths per 1000 deaths.

RISK ASSESSMENT BASED ON THE RESULTS OF LOW EXPOSURE STUDIES

There are three large epidemiological studies $\vec{\Phi}$ workers exposed mainly to low concentrations 亩 benzene,,$^{303133}$ Thorpe conducted a study of $380 \overline{00}$ workers in petroleum refineries. ${ }^{30}$ Although this stufy has several methodological weaknesses, the study could have detected a risk if there was one. Rushton and Alderson studied the mortality patterns of 35000 male employees with a minimum of one year's cont $\vec{m}$ uous service in the United Kingdom oil industrts There was no excess of leukaemia. A third large stuffy of workers potentially exposed to benzene focused $\mathrm{O}$ the rubber industry. Parkes et al followed up 34000 British rubber workers for whom no increased risks could be detected. ${ }^{33}$ In these three studies combinedo total number of $18+30+31=79$ deaths from leukaemia were observed. A $95 \%$ two sided confidence interval may be calculated around this combined finding, which is:

${ }_{e}[\ln (\mathrm{SMR}) \pm 1.96 \sqrt{1} / \mathrm{obs}]=$

$$
\text { e }(4 \cdot 605 \pm 0 \cdot 1125)=89-
$$

This upper limit can serve as a point of departure the risk assessment. Again no accurate data on past exposures to benzene are available. Since 10 ppmoweds the threshold limit value in the early 1970s, it moy be reasonable to use $5 \mathrm{ppm}$ during a period of ten yeats an estimate of the exposure. Subsequently it is possitite to calculate $b$ in the linear model.

$$
\begin{aligned}
\text { SMR } & =100+b \times d \\
112 & =100+b \times 50 \\
b & =12 / 50=0.24
\end{aligned}
$$

which may be used to calculate the SMR given a to dose of 300 ppm-years.

$$
\begin{aligned}
& \text { SMR }=100+0.24 \times 300 \\
& \text { SMR }=172
\end{aligned}
$$

Since the confidence limits were based on to leukaemia mortality, it seems appropriate extrapolate for total leukaemia mortality, even though the risk is probably restricted to acute non-lymphatic leukaemia. The age adjusted death rate for to: 1 leukaemia among men in The Netherlands is 7.6 per 100000 . The total mortality is 923.2 per 10000 . which implies that $8 \cdot 2$ deaths per 1000 deaths will be due to leukaemia if no exposure to benzene occurs. Thus in a group of workers experiencing a dose of 3 ppm-years of benzene, associated with an estimat SMR of $172,8.7 \times 1.72=15$ deaths from leukaemia may occur, of which 8.7 are attributable to the "natural" background incidence of leukaemia.

By analogy, a risk assessment may be made limitififg 
the potential risk to acute non-lymphatic leukaemia. This perspective is probably more realistic given the observations cited earlier in this article.

In The Netherlands the annual age adjusted death rate from acute non-lymphatic leukaemia is 1.6 per 100000 men. For total leukaemia this rate is 7.6 per 100000 men, which implies that approximately $21 \%$ of deaths from leukaemia occurring in men are of the acute non-lymphatic type. Thus generalising this figure to the three low exposure studies, an estimated $17(21 \%)$ of the 79 deaths from leukaemia observed in these studies may have been of the acute nonlymphatic type giving a two sided $95 \%$ confidence interval of 62-161 for the SMR. This upper limit may again serve as the SMR resulting from a benzene dose of $50 \mathrm{ppm}$-years. Next $\mathrm{b}$ may be calculated:

$$
\begin{aligned}
\text { SMR } & =100+b \times d \\
161 & =100+b \times 50 \\
b & =61 / 50=1.22
\end{aligned}
$$

If a dose of $300 \mathrm{ppm}$-years is experienced an SMR for acute non-lymphatic leukaemia may be estimated by means of the linear model as follows:

$$
\text { SMR }=100+1.21 \times 300=466
$$

This implies that instead of the 1.7 deaths from acute non-lymphatic leukaemia an estimated eight deaths may occur per 1000 deaths, of which 1.7 are attributable to the "natural" background incidence of acute non-lymphatic leukaemia.

\section{Discussion}

There is no doubt that relatively long exposure to high concentrations of benzene increases the risk of dying from acute non-lymphatic leukaemia. This observation has frequently been confirmed in epidemiological studies. In studies of workers exposed to low concentrations, however, this relation has been absent or was confined to those workers who had been exposed to high concentrations in the past. It did not seem justified to disregard these negative findings in risk assessments as being merely an effect of methodological shortcomings in these studies. Several risk assessments have been conducted, giving risks in the range of 50 excess deaths from leukaemia per 1000 deaths among workers exposed to 300 ppm-years of benzene. The risk assessment presented in this article clearly leads to lower results than, for instance, the one prepared by Austin et al. ${ }^{15}$ Both assessments are based on several assumptions which are difficult, if not impossible, to verify. Thus it remains of great importance to conduct updates of cohorts already identified as having been exposed to benzene. Although it is up to the policy makers to decide whether or not to alter the current occupational standard, perhaps a guideline might be given as to what level of risk would be regarded as acceptable in an occupational setting. This is more a matter of ethics than of science. Nevertheless, it should be remembered that benzene is not the only chemical to which workers can be exposed, and that the interindividual susceptibility for the haematapoietic effects of benzene can differ widely. Perhaps one additional death per 1000 deaths after a working life of exposure can serve as a guideline.

Requests for reprints to: G M H Swaen, Department of Occupational and Environmental Health and Toxicology, University of Limburg, PO Box 616, 6200 MD Maastricht, The Netherlands.

\section{References}

1 Maltoni C, Conti B, Cotti G. Benzene: a multi-potential carcinogen. Results of long-term bioassays performed at the Bologna Institute of Oncology. Am J Ind Med 1983;4:589-630.

2 Cronkite EP, Bullis JE, Inoue T, Drew RT. Benzene inhalation produces leukaemia in mice. Toxicol Appl Pharmacol 1984;75:358-61.

3 Maltoni C, Scarnato C. First experimental demonstration of the carcinogenic effects of benzene: long-term bioassays on Sprague-Dawley rats by oral administration. Med Lav 1979;70:353-7.

4 Aksoy M, Dincol K, Erdem S, Dincol G. Acute leukemia due to chronic exposure to benzene. Am J Med 1972;52:160-6.

5 Infante PF, Wagoner JK, Rinski RA, Young R. Leukemia in benzene workers. Lancet $1977 ; \mathrm{i}: 76-8$.

6 Ott MG, Townsend JC, Fisbeck WA, Langner RA. Mortality among individuals occupationally exposed to benzene. Arch Environ Health 1978;33:3-10.

7 Rinsky RA, Smith AB, Hornung R, et al. Benzene and leukaemia. $N$ Engl J Med 1987;316:1044-50.

8 Paganini-Hill A, Glazer E, Henderson BE. Cause specific mortality among newspaper web press men. J Occup Med 1980;22:542-4.

9 Monson RR, Fing JL. Cancer mortality and morbidity among rubber workers. J Natl Cancer Inst 1978;61:1947-53.

10 Yin SN, Li GL, Tain FD, et al. Leukaemia in benzene workers: a retrospective cohort study. Br J Ind Med 1987;44:124-8.

11 White AC, Infante PF, Chu KC. A quantitative estimate of leukaemia mortality associated with occupational exposure to benzene. Risk Analysis 1982;2:195-204.

12 Albert RE. Carcinogen assessment group's final report on population risk to ambient benzene exposures. Research Triangle Park NC: EPA, 1979. (EPA 450/5-80-004.)

13 Rinsky RA, Smith AB, Hornung R, et al. Benzene and leukaemia: an epidemiologic risk assessment. $N$ Engl $J$ Med 1987;316: 1044-50.

14 Crump KS, Allen BC. Quantitative estimates of risk of leukemia from occupational exposure to benzene. Cincinnati: Occupational Safety and Health Administration, 1984.

15 Austin H, Dellzell E, Cole P. Benzene and leukemia: a review of the literature and a risk assessment. Am J Epidemiol 1988;127: 419-39.

16 Lutz WK, Schlatter CH. Mechanism of the carcinogenic action of benzene: irreversible binding to rat liver DNA. Chem Biol Interact 1977;18:241-5.

17 Gill DP, Ahmed AE. Covalent binding of carbon 14-labelled benzene to cellular organelles and marrow nucleic acids. Biochem Pharmacol 1981;30:1127-32.

18 Arfellini G, Grilli S, Colacci A, Mazzullo M, Prodi G. In vivo and in vitro binding of benzene to nucleic acids and proteins of 
various rat and mouse organs. Cancer Lett 1985;28:159-68.

19 Rushmore TH, Snyder R, Kalf GF. Covalent binding of benzene and its metabolites to DNA in rabbit bone marrow mitochondria in vitro. Chem Biol Interact 1984;49:133-54.

20 Kalf GF, Snyder R, Rushmore TH. Inhibition of DNA synthesis by benzene metabolites and their covalent binding to DNA in rabbit bone marrow mitochondria in vitro. Am J Ind Med 1985;7:485-92.

21 Probst GS, McMahon RE, Holl LE, Thompson CZ, Epp JK, Neal SB. Chemically-induced DNA synthesis in primary rat. hepatocyte cultures: a comparison with bacterial mutagenicity using 218 compounds. Environ Mutagen 1981;3:11-32.

22 Barret RH. Assays for unscheduled DNA synthesis in Hela 53 cells. In: Ashby J, Serres FJ de, Draper M, et al, eds. Evaluation of short-term tests for carcinogens: report of the international programme on chemical safety collaborative study on in vitro assays. Amsterdam: Elsevier, 1985:347-52.

23 Rijksinstituut voor Volksgezondheid en Milieuhygiëne. (National Institute of Public Health and Environmental Hygiene.) Ontwerp basis-dokument benzeen. Bilthoven: RVM, 1986. (Rapport No 840760002.)

24 Ashby J, Serres FJ de, Draper M, et al, eds. Evaluation of shortterm tests for carcinogens: report on the international program on chemical safety collaborative study on in vitro assays. Amsterdam: Elsevier, 1985.

25 Tice RR, Sawey MJ, Drew RT, Cronkite EP. Benzene-induced micronuclei in the peripheral blood of mice; a retrospective analysis. Environ Mutagen 1984;6:421-4.

26 Dean BJ. Recent findings on the genetic toxicology of benzene, toluene, xylenes and phenols. Mutat Res 1985;154:153-81.

27 Amacher DE, Zelljadt J. The morphological transformation of Syrian hamster embryo cells by chemicals reported non- mutagenic to Salmonella typhimurium. Carcinogenes $\widehat{B}$ 1983;4:291-5.

28 McGregor D, Ashby J. Summary report on the performance of the cell transformation assays. In: Ashby J, Serres de FJ, Draper M, eds. Evaluation of short-term tests for carcinogens: report of the: international programme on chemical safety collaborative studif on in vitro assays. Amsterdam: Elsevier, 1985:103-15.

29 Maltoni C, Conti B, Cotti G, et al. Experimental studies of benzene carcinogenicity at the Bologna Institute of Oncologyen. current results and ongoing research. Am J Ind Med 1985; 441-6.

30 Thorpe JJ. Epidemiological survey of leukaemia in persons potentially exposed to benzene. J Occup Med 1974;16:375-82.

31 Rushton $\mathrm{L}$, Alderson $\mathrm{M}$. The influence of occupation on health Some results from a study in the UK oil industry. Carcinogenesis. 1980;1:739-43.

32 Rushton L, Alderson MR. A case-control study to investigate tho association between exposure to benzene and deaths from leukaemia in oil refinery workers. Br J Cancer 1981;43:77-84. $\frac{\mathbb{1}}{7}$

33 Parkes HG, Veys CA, Waterhouse JAH, Peters A. Cance mortality in the British rubber industry. $\mathrm{Br} \mathrm{J}$ Ind Me芶 1982;39:209-20.

34 Hernberg S. Negative results in cohort studies-how to recognis $\overrightarrow{\mathrm{U}}$ fallacies. Scand J Work Environ Health 1981;7:121-6.

35 European Chemical Industry Ecology and Toxicology Centre. \$ review of recent literature on the toxicology of benzene. Brussels ECETOC, 1984. (Tech report No 16.)

36 Swaen GMH, Hollander de AEM, Kroes R, et al. A scientific basis for the risk assessment of vinyl chloride. Regul Toxicop Pharmacol 1987;7:120-7.

37 Central Bureau of Statistics. Atlas of cancer mortality in The Netherlands. The Hague: Staatsuitgeverij, 1980. 